\title{
Patient-Specific Anatomical and Functional Parameters Provide New Insights into the Pathomechanism of Cam FAI
}

\author{
K. C. Geoffrey Ng MASc, Mario Lamontagne PhD, \\ Andrew P. Adamczyk MSc, Kawan S. Rahkra MD, \\ Paul E. Beaulé MD
}

Published online: 22 July 2014

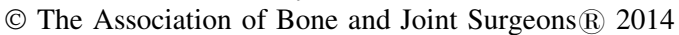

\begin{abstract}
Background Femoroacetabular impingement (FAI) represents a constellation of anatomical and clinical features, but definitive diagnosis is often difficult. The high prevalence of cam deformity of the femoral head in the asymptomatic population as well as clinical factors leading to the onset of symptoms raises questions as to what other factors increase the risk of cartilage damage and hip pain.
\end{abstract}

One or more of the authors (ML, KSR, PEB) have received funding from the Canadian Institutes of Health Research.

All ICMJE Conflict of Interest Forms for authors and Clinical Orthopaedics and Related Research ${ }^{\circledR}$ editors and board members are on file with the publication and can be viewed on request.

Clinical Orthopaedics and Related Research ${ }^{\mathbb{R}}$ neither advocates nor endorses the use of any treatment, drug, or device. Readers are encouraged to always seek additional information, including FDAapproval status, of any drug or device prior to clinical use. Each author certifies that his or her institution has approved the human protocol for this investigation, that all investigations were conducted in conformity with ethical principles of research, and that informed consent for participation in the study was obtained. This work was performed at the Human Movement Biomechanics Laboratory, University of Ottawa, and at The Ottawa Hospital, Ottawa, Ontario, Canada.

Electronic supplementary material The online version of this article (doi:10.1007/s11999-014-3797-1) contains supplementary material, which is available to authorized users.

K. C. G. Ng, M. Lamontagne

Department of Mechanical Engineering, University of Ottawa, Ottawa, ON, Canada

M. Lamontagne

School of Human Kinetics, University of Ottawa, Ottawa, ON, Canada

A. P. Adamczyk

Faculty of Medicine, University of Ottawa, Ottawa, ON, Canada
Questions/purposes The purpose was to identify any differences in anatomical parameters and squat kinematics among symptomatic, asymptomatic, and control individuals and if these parameters can determine individuals at risk of developing symptoms of cam FAI.

Methods Forty-three participants $(\mathrm{n}=43)$ were recruited and divided into three groups: symptomatic (12), asymptomatic (17), and control (14). Symptomatic participants presented a cam deformity (identified by an elevated alpha angle on CT images), pain symptoms, clinical signs, and were scheduled for surgery. The other recruited volunteers were blinded and unaware whether they had a cam deformity. After the CT data were assessed for an elevated alpha angle, participants with a cam deformity but who did not demonstrate any clinical signs or symptoms were considered asymptomatic, whereas participants without a cam deformity and without clinical signs or symptoms were considered healthy control subjects. For each participant, anatomical CT parameters (axial alpha angle, radial alpha angle, femoral head-neck offset, femoral neck-shaft angle, medial proximal femoral angle, femoral torsion, acetabular version) were evaluated. Functional squat parameters (maximal squat depth, pelvic range of motion) were determined using a motion capture system. A stepwise discriminant function analysis was used to determine

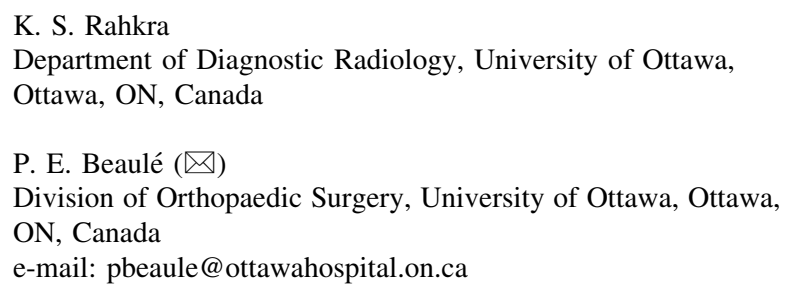


which of the parameters were most suitable to classify each participant with their respective subgroup.

Results The symptomatic group showed elevated alpha angles and lower femoral neck-shaft angles, whereas the asymptomatic group showed elevated alpha angles in comparison with the control group. The best discriminating parameters to determine symptoms were radial alpha angle, femoral neck-shaft angle, and pelvic range of motion $(\mathrm{p}<0.001)$.

Conclusions In the presence of a cam deformity, indications of a decreased femoral neck-shaft angle and reduced pelvic range of motion can identify those at risk of symptomatic FAI.

Level of Evidence Level III, diagnostic study. See the Guidelines for Authors for a complete description of levels of evidence.

\section{Introduction}

Cam-type femoroacetabular impingement (FAI), characterized by an enlarged, aspherical deformity of the femoral head and neck, is recognized as a pathomechanical disease process of the hip and a possible cause for early adult osteoarthritis [1, 16, 23]. This mechanical impingement is typically observed at the limit of ROM [31, 32] when the aspherical femoral head comes into contact with lateral aspects of the anterosuperior labrum and acetabulum. In the presence of a larger cam deformity, it further reduces the clearance between the femoral head-neck junction and the labrum, therefore imposing an obstruction and inducing elevated stresses [35].

Defining who is at risk of impingement and cartilage damage has been mainly based on the size and location of the cam deformity, which has been traditionally quantified by the alpha angle on multiplane imaging [3, 7, 36, 37, 39, $43,45]$. Several authors have shown that the severity of the cam deformity (that is, a higher alpha angle) is associated with an increased risk of hip pain and joint degeneration [7, $28,33]$. Typically, a cam deformity is indicated by an alpha angle greater than $50.5^{\circ}$ and $60^{\circ}$ in the oblique-axial and radial plane, respectively [7, 36, 37, 39]. However, the accuracy and sensitivity of the alpha angle in determining the risk of developing symptomatic FAI is inconsistent [6, 30, 34, 37, 43]. Moreover, other common radiographic measures of the femoral head and neck and acetabulum have been associated with symptomatic FAI [5, 10, 26, 40], but it remains unclear as to which combination of parameters plays a role in identifying patients at risk of developing symptoms. Although patients have demonstrated higher hip stresses [35] and different hip kinematics at higher ROMs such as during maximal squatting [31, 32], it is still unclear why many individuals with cam deformity do not exhibit any clinical signs [22, 38, 40].

Many individuals with cam deformities may not experience mechanical impingement or pain symptoms, thus qualifying them as asymptomatic individuals [11, 18, 26, 43]. Therefore, we postulated that FAI symptoms may be related to other anatomical parameters that can exacerbate mechanical impingement in patients at risk of developing symptoms.

The purpose of this study was to examine other anatomical features of the hip that could be associated with symptoms resulting from the cam deformity. In this study, we addressed two research questions: (1) Can additional anatomical parameters, in addition to the conventional alpha angles, and functional squat parameters determine differences among symptomatic, asymptomatic, and control individuals? (2) Which of the anatomical and functional squat parameters best classify symptomatic, asymptomatic, and control individuals with their respective subgroups and identify patients at risk of developing symptoms?

\section{Patients and Methods}

Initially, 50 male volunteers were recruited in a 2-year period through the hospital's Division of Orthopaedic Surgery. The participants were classified based on indications of a cam deformity on CT scans, clinical impingement signs, and plans to undergo hip surgery. Symptomatic participants with the deformity, who presented themselves with hip pain and clinical signs of impingement, were recruited from the orthopaedic surgeon's clinical practice once scheduled for surgery. Additional participants volunteered for the study and were blinded and unaware whether they had a cam deformity. Pelvic and knee CT data were acquired from each participant using either a Toshiba Acquilion (Toshiba Medical Systems Corporation, Otawara, Japan) or a GE Discover CT750 (GE Healthcare, Mississauga, Ontario, Canada) and observed for a cam deformity, as indicated by an elevated alpha angle, by a musculoskeletal radiologist (KSR). After the CT data were assessed, participants with a cam deformity but who did not demonstrate any clinical signs or symptoms were considered asymptomatic. Participants without a cam deformity and without any clinical signs or symptoms were considered as healthy control subjects. Participants with any neurological or musculoskeletal disorders, degenerative diseases, previous major lower limb injuries, or a body mass index greater than $30 \mathrm{~kg} / \mathrm{m}^{2}$ were excluded.

This a priori classification resulted in 15 symptomatic, 19 asymptomatic, and 16 control participants. All 
participants completed pain questionnaires to ascertain their Hip Disability and Osteoarthritis Outcome Score and WOMAC. Participants signed and provided informed consent before the study. The university and hospital research institute ethics boards approved this study and all investigations were conducted ethically in conformity with research principles.

To remove bias from a priori classifications, CT data were then blinded and randomly assigned new file names. Both left and right hips were measured for multiple anatomical CT measures, which included axial alpha angle, radial alpha angle, femoral head-neck offset, femoral neckshaft angle, medial proximal femoral angle, femoral torsion, and acetabular version using Onis 2.4 (DigitalCore, Tokyo, Japan). To confirm the reliability of the measurements, two observers (KCGN, APA) evaluated the anatomical $\mathrm{CT}$ parameters, each performing two readings. Both observers received training and instructions from a musculoskeletal radiologist (KSR). Each observer's second reading was performed 2 weeks after the completion of the first.

The axial alpha angle was measured on the oblique-axial plane of the longitudinal femoral neck axis, observing for the cam deformity in the anterior aspect of the femoral head [36]. With the vertex centered at the femoral head, the angle measured the femoral neck axis to the head-neck junction (Fig. 1A). Anterior femoral head-neck offset was also observed on the oblique-axial plane [11, 26], measuring the offset distance between the two tangents of the anterior femoral head and neck (Fig. 1A). The radial alpha angle was obtained through a 1:30 clockface rotation about the longitudinal femoral neck axis [39, 43], observing the anterosuperior quadrant (Fig. 1B). An axial alpha angle greater than $50.5^{\circ}$ or radial alpha angle greater than $60^{\circ}$ was considered as cam deformity $[6,43]$.

The femoral neck-shaft angle, from the frontal plane, was formed between the femoral neck and shaft axes (Fig. 1C) [22, 40]. Similarly, the medial proximal femoral angle was measured between the femoral shaft axis and the line joining the center of the femoral head to the superior greater trochanter (Fig. 1D) [5]. Femoral torsion was determined as the difference between the femoral neck horizontal and condyle horizontal angles, each taking the angle with respect to the transverse plane's horizontal plane (Fig. 1E-F) [10, 15]. Acetabular version was measured on the transverse plane coincident with the left and right femoral head centers $[11,12,41]$. This angle was formed by the line connecting the anterior and posterior acetabular notches and the perpendicular axis to the posterior acetabular notch (Fig. 1G).

Detailed measurement protocols for each anatomical parameter were provided to the observers before the readings (Supplemental materials are available with the online version of CORR ${ }^{\circledR}$.).

Three-dimensional (3-D) hip kinematics were collected from each participant's maximal squat depth motion using 10 Vicon MX-13 cameras (Vicon, Los Angeles, CA, USA) and retroreflective skin markers placed on anatomical landmarks using a modified Helen-Hayes marker set [13, 25]. Participants were instructed to perform five maximal dynamic squats, squatting to the lowest possible depth at a controlled, self-selected pace. Feet were placed shoulderwidth apart, directed anteriorly, with toes and heels in full contact with the ground during the entire squat cycle [31,
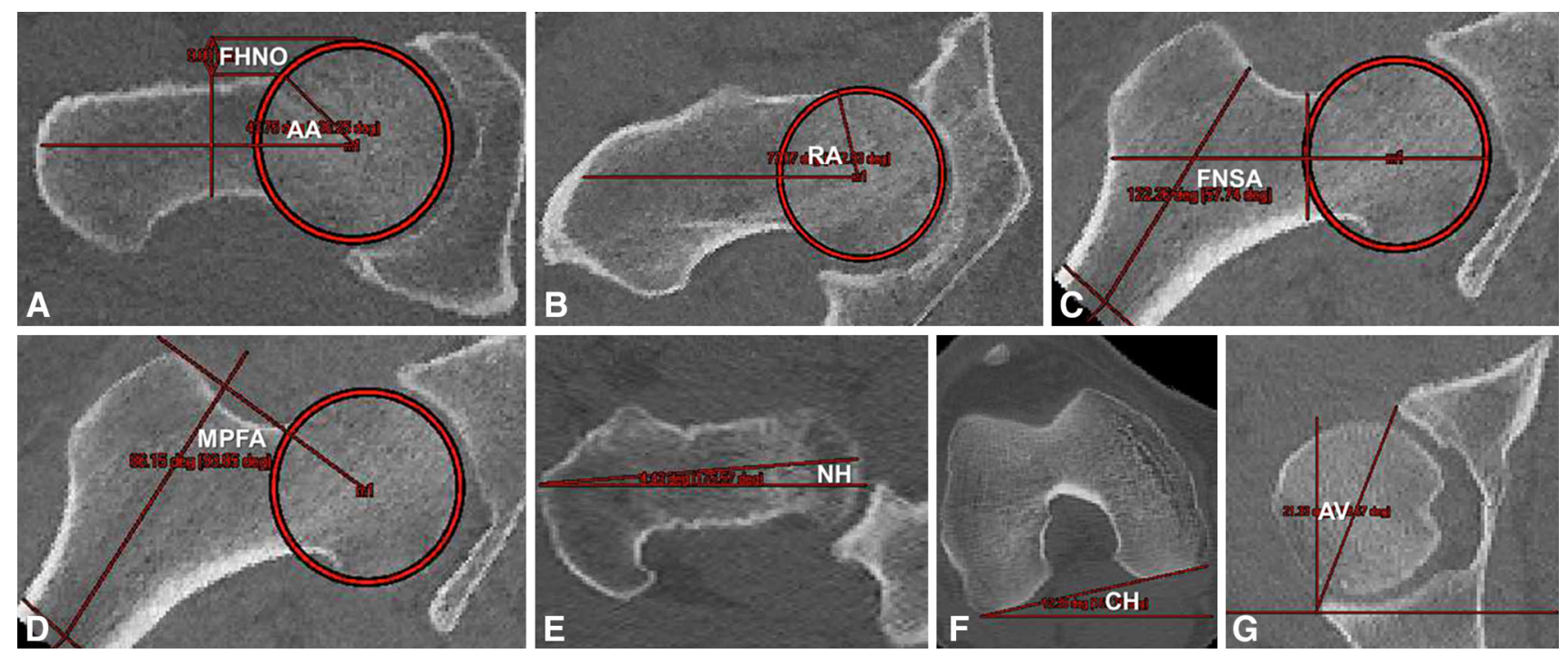

Fig. 1A-G Anatomical CT parameters measure the axial alpha angle (AA), femoral head-neck offset (FHNO) (A), radial alpha angle (RA) (B), femoral neck-shaft angle (FNSA) (C), medial proximal femoral angle (MPFA) (D), neck (NH) (E) and condyle horizontals $(\mathrm{CH})$ (F) for femoral torsion, and acetabular version (AV) (G). 
32]. Five squat depths were averaged as a percentage with respect to leg height, where ground level represented a leg height of $0 \%$. Total sagittal pelvic ROM was calculated from peak pelvic angles during descent, maximal squat, and ascent phases.

The resultant $\mathrm{CT}$ measurements were then unblinded and matched with the squat results. For each of the symptomatic, asymptomatic, or control participants, the affected side was defined by the side with symptoms, higher alpha angle, or smaller alpha angle, respectively. Five participants (three symptomatic, one asymptomatic, one control) were excluded as a result of their inability to perform an adequate deep squat ( $<70 \%$ of leg height). A gray zone range for the alpha angles was defined to account for potential reading errors (axial $=50.5^{\circ} \pm 3^{\circ}$; radial $=$ $60^{\circ} \pm 3^{\circ}$ ). Two participants (one asymptomatic, one control) were excluded as a result of their alpha angles being within this gray zone. This resulted in a final sample size of 43 participants $(n=43)$, with 12 symptomatic, 17 asymptomatic, and 14 control participants.

For each anatomical CT measure, intra- and interrater reliability was quantified using the intraclass correlation coefficient (ICC) using two-way mixed models. Intrarater considered single measures whereas interrater considered average measures, both seeking absolute agreement [19, 42]. The intra- and interrater anatomical observations were in strong to near-perfect agreement $\left(0.847 \leq \mathrm{ICC}_{\mathrm{Obs} 1}\right.$ $\leq 0.987 ; \quad 0.867 \leq \mathrm{ICC}_{\text {Obs } 2} \leq 0.967 ; \quad 0.703 \leq \mathrm{ICC}_{\text {Obs } 1-2}$ $\leq 0.886$; Table 1). To examine if there were differences among each of the anatomical and functional parameters among the groups, a one-way between-groups analysis of variance was used $(\alpha=0.05)$. A stepwise discriminant function analysis (DFA) was implemented to identify which of the anatomical and squat kinematics parameters were most suitable to classify each participant's affected hip with their respective subgroup. Similar to a hierarchical linear regression, where multiple parameters describe the level of variance, the DFA further predicts how subjects are classified based on the most suitable parameters. Sample

Table 1. Intraclass correlation coefficient indicating the intra- and interrater reliability for each measured anatomical CT parameter

\begin{tabular}{llll}
\hline Anatomical parameter & Intrarater 1 & Intrarater 2 & Interraters 1-2 \\
\hline Axial alpha angle & 0.957 & 0.948 & 0.881 \\
Radial alpha angle & 0.972 & 0.929 & 0.865 \\
Femoral neck-shaft angle & 0.847 & 0.867 & 0.854 \\
$\begin{array}{l}\text { Medial proximal femoral } \\
\quad 0.969\end{array}$ & 0.904 & 0.783 \\
$\quad$ Femgle & & & \\
Femoral head-neck offset & 0.927 & 0.903 & 0.758 \\
Acetabular version & 0.987 & 0.916 & 0.703 \\
\hline
\end{tabular}

sizes were deemed adequate because the smallest group size (12) exceeded the number of total parameters (nine) [44]. The DFA assumed that each of the anatomical CT and squat parameters was treated as an independent variable for grouping. Statistical analysis was performed using SPSS Statistics Version 21 (IBM Corporation, Armonk, NY, USA).

\section{Results}

Other than the alpha angles and femoral head-neck offset, characteristic parameters of the cam deformity, the asymptomatic group demonstrated similar anatomical and squat parameters as the control group (Table 2). Both symptomatic and asymptomatic groups demonstrated higher axial alpha angles $\left(56^{\circ} \pm 8^{\circ}\right.$ and $57^{\circ} \pm 8^{\circ}$, respectively), radial alpha angles $\left(67^{\circ} \pm 6^{\circ}\right.$ and $71^{\circ} 7 \pm 6^{\circ}$, respectively), and lower femoral head-neck offsets $(6 \pm 2 \mathrm{~mm}$ and $7 \pm 2 \mathrm{~mm}$, respectively) in comparison with the control group $\left(\right.$ axial $=43^{\circ} \pm 3^{\circ}, \eta^{2}=0.517, \mathrm{p}<0.001 ;$ radial $=52^{\circ}$ $\pm 4^{\circ}, \quad \eta^{2}=0.705, \quad \mathrm{p}<0.001 ; \quad$ offset $=9 \pm 1 \mathrm{~mm}$, $\left.\eta^{2}=0.440, \mathrm{p}<0.001\right)$. Femoral neck-shaft angles were higher for the asymptomatic and control groups $\left(127^{\circ} \pm 3^{\circ}\right.$ and $128^{\circ} \pm 2^{\circ}$, respectively) in comparison with the symptomatic group $\left(123^{\circ} \pm 2^{\circ}, \eta^{2}=0.496, p<0.001\right)$. The symptomatic group showed prominent femoral antetorsion $\left(\eta^{2}=0.164, p=0.039\right)$ in comparison with the control group, but did not show any differences in medial proximal femoral angle or acetabular version. Moreover, the symptomatic group had a substantially reduced squat depth $(44 \% \pm 10 \%)$ and pelvic $\mathrm{ROM}\left(11^{\circ} \pm 4^{\circ}\right)$ in comparison with the asymptomatic $\left(39 \% \pm 9 \% ; 15^{\circ} \pm 7^{\circ}\right)$ and control groups $\left(37 \% \pm 8 \% ; 15^{\circ} \pm 7^{\circ}\right)$.

The best parameters to classify the participants and to determine symptoms were radial alpha angle, femoral neck-shaft angle, and pelvic ROM. The three-step DFA included radial alpha angle in the first step (Wilk's $\left.\lambda_{1}=0.295, \mathrm{p}<0.001\right)$, femoral neck-shaft angle in the second (Wilk's $\lambda_{2}=0.157, \mathrm{p}<0.001$ ), then pelvic ROM in the third (Wilk's $\lambda_{3}=0.135, \mathrm{p}<0.001$ ). The resultant two predictive equations based on the standardized canonical discriminant function coefficients were:

$$
\text { Function } \begin{aligned}
1= & (0.962 \cdot z R A)-(0.156 \cdot z F N S A) \\
& -(0.050 \cdot z R O M)
\end{aligned}
$$

Function $2=(0.325 \cdot z R A)+(0.973 \cdot z F N S A)$

$$
+(0.517 \cdot z R O M)
$$

where $\mathrm{zRA}$, zFNSA, and zROM represent the standardized normal scores of their respective measures. Inputting an 
Table 2. Descriptive anatomical CT parameters, squat depth parameters, and pain scores associated with the symptomatic, asymptomatic, and control groups

\begin{tabular}{|c|c|c|c|c|}
\hline Group descriptive & Symptomatic & Asymptomatic & Control & Total \\
\hline Number of participants & 12 & 17 & 14 & 43 \\
\hline Age (years) & $38 \pm 9$ & $31 \pm 5$ & $32 \pm 6$ & $33 \pm 7$ \\
\hline Body mass index $\left(\mathrm{kg} / \mathrm{m}^{2}\right)$ & $26 \pm 3$ & $25 \pm 2$ & $26 \pm 3$ & $26 \pm 3$ \\
\hline \multicolumn{5}{|l|}{ Anatomical parameter } \\
\hline Axial alpha angle $\left(^{\circ}\right)$ & $56 \pm 8^{*}$ & $57 \pm 8^{*}$ & $43 \pm 3$ & $52 \pm 9$ \\
\hline Radial alpha angle $\left(^{\circ}\right)$ & $67 \pm 6^{*}$ & $71 \pm 6^{*}$ & $52 \pm 4$ & $64 \pm 10$ \\
\hline Femoral head-neck offset (mm) & $6 \pm 2 *$ & $7 \pm 2 *$ & $9 \pm 1$ & $7 \pm 2$ \\
\hline Femoral neck-shaft angle $\left({ }^{\circ}\right)$ & $123 \pm 2^{*}, \dagger$ & $127 \pm 3$ & $128 \pm 2$ & $126 \pm 3$ \\
\hline Medial proximal femoral angle $\left(^{\circ}\right)$ & $80 \pm 4$ & $83 \pm 4$ & $82 \pm 4$ & $82 \pm 4$ \\
\hline Femoral torsion $\left(^{\circ}\right)$ & $14 \pm 9 *$ & $13 \pm 8$ & $6 \pm 7$ & $11 \pm 8$ \\
\hline Acetabular version $\left({ }^{\circ}\right)$ & $22 \pm 5$ & $18 \pm 4$ & $19 \pm 6$ & $19 \pm 5$ \\
\hline \multicolumn{5}{|l|}{ Maximal squat depth parameter } \\
\hline Depth (percent leg height) & $44 \pm 10$ & $39 \pm 9$ & $37 \pm 8$ & $40 \pm 9$ \\
\hline Pelvic ROM $\left(^{\circ}\right)$ & $11 \pm 4$ & $15 \pm 7$ & $15 \pm 7$ & $14 \pm 6$ \\
\hline \multicolumn{5}{|l|}{ Pain questionnaire } \\
\hline HOOS-pain & $64 \pm 21^{*, \dagger}$ & $99 \pm 5$ & $99 \pm 4$ & $88 \pm 20$ \\
\hline WOMAC-pain & $71 \pm 21^{*, \dagger}$ & $100 \pm 1$ & $99 \pm 3$ & $91 \pm 18$ \\
\hline
\end{tabular}

Values are mean $\pm \mathrm{SD} ; *$ significant difference $(\mathrm{p}<0.05)$ compared with control group; ${ }^{\dagger}$ significant difference $(\mathrm{p}<0.05)$ compared with asymptomatic group; HOOS = Hip Disability and Osteoarthritis Outcome Score.

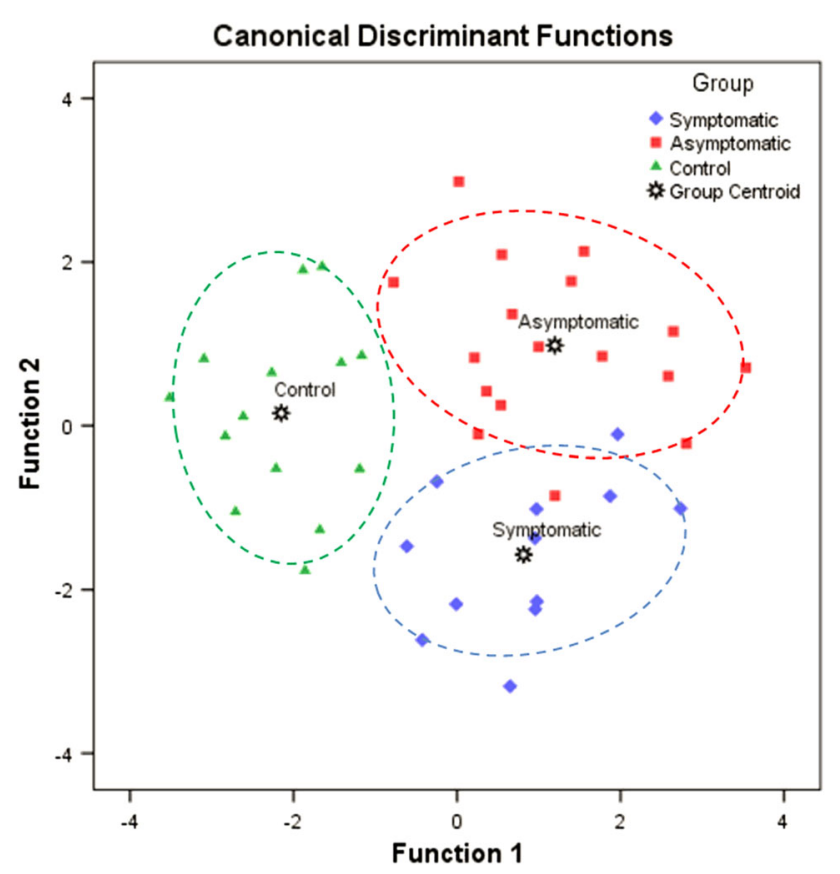

Fig. 2 Discriminant function analysis with canonical discriminant functions classifies symptomatic (diamond), asymptomatic (square), and control (triangle) individuals based on the radial alpha angle, femoral neck-shaft angle, and pelvic ROM. Group envelopes (ellipses) are centered on the group centroids (star markers).

additional participant's radial alpha angle, femoral neckshaft angle, and pelvic ROM z-values into the predictive equations (equations [1] and [2]), the resultant functions would provide a visual indication of classification based on their proximity to a group centroid (Fig. 2). It was determined that $95 \%$ (41 of 43) of the original group was classified correctly. A participant, initially classified as asymptomatic, was reclassified closer to the symptomatic group based on the stepwise parameters. This asymptomatic participant had an elevated radial alpha angle and decreased femoral neck-shaft angle $\left(122^{\circ}\right)$, similar to characteristic mean values of the symptomatic group. Another symptomatic participant was predicted to be significantly closer to the asymptomatic group with a radial alpha angle and femoral neck-shaft angle $\left(125^{\circ}\right)$ closer to the mean values of the asymptomatic group (Fig. 2).

\section{Discussion}

Recent publications have highlighted the prevalence of the cam deformity in the normal population based on the alpha angle $[17,18,24]$. However, we do not know what factors increase the likelihood that a patient with cam FAI morphology will become symptomatic. To better predict which individuals with a cam deformity who are at risk of developing hip symptoms, we used subjectspecific motion analysis as well as additional anatomical parameters in discriminating individuals with and without symptoms. We found that radial alpha angle, femoral neck-shaft angle, and pelvic ROM predicted FAI symptoms. 
One of the limitations was the number of CT parameters considered. Because the focus was on cam-type FAI, we selected common recurring parameters of the proximal femur, as opposed to the acetabulum, postulated to describe characteristics of FAI. To fully understand the relationship among joint structures, clinical signs, and the role of acetabular orientation on joint kinematics, an extensive study of the morphological parameters associated with the acetabulum (eg, lateral center-edge angle and retroversion index) may be needed in the future along with a 3-D shape analysis of the cam deformity [20, 21]. Because the cam morphology is statistically more prevalent in males [2, 9, 27], our sample population consisted of only male participants. The inclusion of females could introduce variances in anatomical structure and squat kinematics. Nonetheless, studies comparing sex in regard to anatomical parameters and motion analysis should be addressed in the future. The differences in age may also have been a limitation, because cartilage and labral damage not only depends on the size of the deformity, but can also increase with age. Although our symptomatic group was slightly older, age differences were not significant and there were a few older symptomatic participants who performed deeper squats and wider pelvic motions. It may have been possible that pelvic ROM was limited by pain. During the maximal dynamic squat, participants were asked if they experienced any discomfort or pain during the motion and none of the patients stated that pain limited their squat capacity. In addition, none of the patients had evidence of osteoarthritis on radiographs. Having said that, we cannot fully account for other possible causes of limited squat such as apprehension by the participant to avoid pain. It is possible that the pace of the squat motion can affect the loading dynamics of the cam deformity onto the articulating surfaces. A subject-specific finite element model, incorporating the viscoelastic characteristics of the cartilage, could be considered in the future to better address the loading dynamics of the hip. The other limitation is the use of pain to help classify the different groups. Because there are multiple sources of pain in and around the hip, we cannot make conclusions as to the risk of eventual hip arthritis. Use of quantitative cartilage MRI may provide further insight into the biomechanical parameters associated with FAI in patients with the cam morphology [4, 8].

We found that the symptomatic group had a substantially smaller femoral neck-shaft angle with angles approaching coxa vara; others have suggested that this can predispose to labral-chondral damage in patients with a cam deformity [10, 14, 45]. In addition, Bedi and associates [10] recognized that shortening of the varus neck resulted in intraarticular and extraarticular mechanical impingement. Hartofilakidis and associates [22] reported a femoral neck-shaft angle for their symptomatic group $\left(119^{\circ}\right)$, which corresponded closely with our findings. Ranawat and associates [40] reported a much higher symptomatic femoral neck-shaft angle $\left(132^{\circ}\right)$ but was still lower than their respective contralateral asymptomatic side. A decrease in femoral neck-shaft angle, although small, could explain symptoms of unilateral FAI [40]. The medial proximal femoral angle for our symptomatic group was not substantially lower than our asymptomatic or control group but was similar to previous findings for progressive osteoarthritis [5]. The medial proximal femoral angle measures between the femoral head-to-neck from the greater trochanter as opposed to the neck-to-shaft angle. The correct CT slice may not have been selected to locate our superior greater trochanter, thus underestimating its implication toward understanding the onset of osteoarthritis. The symptomatic group's femoral torsion corresponded with previous findings, indicating an increased risk for labral damage [15]. However, results for acetabular version were inconclusive because several asymptomatic and control participants demonstrated retroversion but did not show any clinical signs or symptoms. This contradicts previous findings for acetabular version associated with symptoms [12, 26, 29, 41] and may not yet be adequate to explain differences between symptomatic and asymptomatic individuals.

The stepwise DFA indicated that radial alpha angle, femoral neck-shaft angle, and pelvic ROM were the best classifiers. Including other parameters in the stepwise DFA would not have substantially improved the predictive power of the model. Alternatively, all parameters could have been included in the DFA to obtain predictive functions dependent on all anatomical and squat parameters. However, this would not have predicted which parameters were the most suitable for classification and, thus, would not have established characteristics most potentially associated with symptoms. Interestingly, the radial alpha angle was more predictive than the axial alpha angle [43], reiterating that it should be the preferred alpha angle to observe for the increased severity of the cam deformity [6, $7,39,43]$. The femoral neck-shaft angle was considered as a second discriminating parameter to distinguish symptomatic from asymptomatic individuals, because it was substantially different among the two groups. Although medial proximal femoral angle and femoral torsion for the symptomatic group were slightly lower, compared with asymptomatic, the difference was not large enough for the analysis to consider them as discriminating parameters. Pelvic ROM was used as the final parameter to further distinguish symptomatic from asymptomatic individuals. The symptomatic group could not squat as low and had a reduced pelvic ROM in comparison with the other groups, reiterating the implementation of a maximal squat motion as a functional diagnostic test in determining individuals at 
risk of developing hip symptoms. The inclusion of femoral neck-shaft angle reveals that there is an association between the neck orientation with a severe cam deformity and dynamic hip motion, which improves previous understandings of the pathoanatomy $[10,14,46]$. Ultimately, for mechanical impingement to occur as a result of the cam morphology, symptoms could persist attributable to a combination of several anatomical factors. Limited squat depth is reflective of decreased pelvic mobility, putting the hip further at risk of developing pain.

Our findings confirm the complex nature of impingement as well as other anatomical parameters that play important roles in the onset of hip symptomatology. Consequently, providing the clinicians with additional and more specific anatomical measurements (eg, radial alpha angle, femoral neck-shaft angle, pelvic ROM) can identify who is at greater risk of coming to surgical intervention as well as developing screening programs for the cam morphology at risk of FAI.

Acknowledgments We thank Kevin Dwyer and Giulia Mantovani, from the University of Ottawa's Human Movement Biomechanics Laboratory, for their help with data collection and processing. We also thank Jae-Jin Ryu and Gillian Parker, from The Ottawa Hospital's Division of Orthopedic Surgery, for their help with patient recruitment and data collection.

\section{References}

1. Agricola R, Heijboer MP, Bierma-Zeinstra SM, Verhaar JA, Weinans H, Waarsing JH. Cam impingement causes osteoarthritis of the hip: a nationwide prospective cohort study (CHECK). Ann Rheum Dis. 2012;72:918-923.

2. Allen D, Beaule PE, Ramadan O, Doucette S. Prevalence of associated deformities and hip pain in patients with cam-type femoroacetabular impingement. $J$ Bone Joint Surg Br. 2009;91:589-594.

3. Anderson LA, Peters CL, Park BB, Stoddard GJ, Erickson JA, Crim JR. Acetabular cartilage delamination in femoroacetabular impingement. Risk factors and magnetic resonance imaging diagnosis. J Bone Joint Surg Am. 2009;91:305-313.

4. Apprich S, Mamisch TC, Welsch GH, Bonel H, Siebenrock KA, Kim YJ, Trattnig S, Dudda M. Evaluation of articular cartilage in patients with femoroacetabular impingement (FAI) using T2* mapping at different time points at 3.0 Tesla MRI: a feasibility study. Skeletal Radiol. 2012;41:987-995.

5. Bardakos NV, Villar RN. Predictors of progression of osteoarthritis in femoroacetabular impingement: a radiological study with a minimum of ten years follow-up. J Bone Joint Surg Br. 2009;91:162-169.

6. Barton C, Salineros MJ, Rakhra KS, Beaule PE. Validity of the alpha angle measurement on plain radiographs in the evaluation of cam-type femoroacetabular impingement. Clin Orthop Relat Res. 2011;469:464-469.

7. Beaulé P, Hynes K, Parker G, Kemp K. Can the alpha angle assessment of cam impingement predict acetabular cartilage delamination? Clin Orthop Relat Res. 2012;470:3361-3367.

8. Beaulé PE, Kim YJ, Rakhra KS, Stelzeneder D, Brown TD. New frontiers in cartilage imaging of the hip. Instr Course Lect. 2012;61:253-262.
9. Beck M, Kalhor M, Leunig M, Ganz R. Hip morphology influences the pattern of damage to the acetabular cartilage: femoroacetabular impingement as a cause of early osteoarthritis of the hip. J Bone Joint Surg Br. 2005;87:1012-1018.

10. Bedi A, Dolan M, Leunig M, Kelly BT. Static and dynamic mechanical causes of hip pain. Arthroscopy. 2011;27:235-251.

11. Chakraverty JK, Sullivan C, Gan C, Narayanaswamy S, Kamath S. Cam and pincer femoroacetabular impingement: CT findings of features resembling femoroacetabular impingement in a young population without symptoms. AJR Am J Roentgenol. 2013;200:389-395.

12. Dandachli W, Islam SU, Liu M, Richards R, Hall-Craggs M, Witt J. Three-dimensional CT analysis to determine acetabular retroversion and the implications for the management of femoroacetabular impingement. $J$ Bone Joint Surg $\mathrm{Br}$. 2009;91:1031-1036.

13. Davis RB, Ounpuu S, Tyburski D, Gage JR. A gait analysis data collection and reduction technique. Hum Mov Sci. 1991;10:575-587.

14. Doherty M, Courtney P, Doherty S, Jenkins W, Maciewicz RA, Muir K, Zhang W. Nonspherical femoral head shape (pistol grip deformity), neck shaft angle, and risk of hip osteoarthritis: a casecontrol study. Arthritis Rheum. 2008;58:3172-3182.

15. Ejnisman L, Philippon M, Lertwanich P, Pennock A, Herzog M, Briggs K, Ho C. Relationship between femoral anteversion and findings in hips with femoroacetabular impingement. Orthopedics. 2013;36:293-300.

16. Ganz R, Parvizi J, Beck M, Leunig M, Nötzli H, Siebenrock KA. Femoroacetabular impingement: a cause for osteoarthritis of the hip. Clin Orthop Relat Res. 2003;417:112-120.

17. Gosvig KK, Jacobsen S, Palm H, Sonne-Holm S, Magnusson E. A new radiological index for assessing asphericity of the femoral head in cam impingement. $J$ Bone Joint Surg Br. 2007;89:1309-1316.

18. Hack K, Di Primio G, Rakhra K, Beaule PE. Prevalence of camtype femoroacetabular impingement morphology in asymptomatic volunteers. J Bone Joint Surg Am. 2010;92:2436-2444.

19. Hallgren KA. Computing inter-rater reliability for observational data: an overview and tutorial. Tutor Quant Methods Psychol. 2012;8:23-34.

20. Harris MD, Datar M, Whitaker RT, Jurrus ER, Peters CL, Anderson AE. Statistical shape modeling of cam femoroacetabular impingement. J Orthop Res. 2013;31:1620-1626.

21. Harris MD, Reese SP, Peters CL, Weiss JA, Anderson AE. Threedimensional quantification of femoral head shape in controls and patients with cam-type femoroacetabular impingement. Ann Biomed Eng. 2013;41:1162-1171.

22. Hartofilakidis G, Bardakos NV, Babis GC, Georgiades G. An examination of the association between different morphotypes of femoroacetabular impingement in asymptomatic subjects and the development of osteoarthritis of the hip. J Bone Joint Surg Br. 2011;93:580-586.

23. Ito K, Leunig M, Ganz R. Histopathologic features of the acetabular labrum in femoroacetabular impingement. Clin Orthop Relat Res. 2004;429:262-271.

24. Jung KA, Restrepo C, Hellman M, AbdelSalam H, Morrison W, Parvizi J. The prevalence of cam-type femoroacetabular deformity in asymptomatic adults. $J$ Bone Joint Surg Br. 2011;93:1303-1307.

25. Kadaba MP, Ramakrishnan HK, Wootten ME. Measurement of lower extremity kinematics during level walking. J Orthop Res. 1990;8:383-392.

26. Kang AC, Gooding AJ, Coates MH, Goh TD, Armour P, Rietveld J. Computed tomography assessment of hip joints in asymptomatic individuals in relation to femoroacetabular impingement. Am J Sports Med. 2010;38:1160-1165. 
27. Kassarjian A, Brisson M, Palmer WE. Femoroacetabular impingement. Eur J Radiol. 2007;63:29-35.

28. Khanna V, Cariagani A, Rakhra K, Di Primio G, Beaule PE. Incidence of hip pain in a prospective cohort of asymptomatic volunteers: is the cam deformity a risk factor for hip pain? Am J Sports Med. 2014;42:793-797.

29. Kim WY, Hutchinson CE, Andrew JG, Allen PD. The relationship between acetabular retroversion and osteoarthritis of the hip. J Bone Joint Surg Br. 2006;88:727-729.

30. Konan S, Rayan F, Haddad FS. Is the frog lateral plain radiograph a reliable predictor of the alpha angle in femoroacetabular impingement? J Bone Joint Surg Br. 2010;92:47-50.

31. Lamontagne M, Brisson N, Kennedy MJ, Beaule PE. Preoperative and postoperative lower-extremity joint and pelvic kinematics during maximal squatting of patients with cam femoro-acetabular impingement. J Bone Joint Surg Am. 2011;93(Suppl 2):40-45.

32. Lamontagne M, Kennedy MJ, Beaule PE. The effect of cam FAI on hip and pelvic motion during maximum squat. Clin Orthop Relat Res. 2009;467:645-650.

33. Larson CM, Giveans MR. Arthroscopic management of femoroacetabular impingement: early outcomes measures. Arthroscopy. 2008;24:540-546.

34. Lohan DG, Seeger LL, Motamedi K, Hame S, Sayre J. Cam-type femoral-acetabular impingement: is the alpha angle the best MR arthrography has to offer? Skeletal Radiol. 2009;38:855-862.

35. Ng KCG, Rouhi G, Lamontagne M, Beaulé PE. Finite element analysis examining the effects of cam FAI on hip joint mechanical loading using subject-specific geometries during standing and maximum squat. HSS J. 2012;8:206-212.

36. Nötzli HP, Wyss TF, Stoecklin CH, Schmid MR, Treiber K, Hodler J. The contour of the femoral head-neck junction as a predictor for the risk of anterior impingement. J Bone Joint Surg Br. 2002;84-B:556-560.

37. Nouh MR, Schweitzer ME, Rybak L, Cohen J. Femoroacetabular impingement: can the alpha angle be estimated? AJR Am J Roentgenol. 2008;190:1260-1262.

38. Pollard TC, Villar RN, Norton MR, Fern ED, Williams MR, Simpson DJ, Murray DW, Carr AJ. Femoroacetabular impingement and classification of the cam deformity: the reference interval in normal hips. Acta Orthop. 2010;81:134-141.

39. Rakhra KS, Sheikh AM, Allen D, Beaule PE. Comparison of MRI alpha angle measurement planes in femoroacetabular impingement. Clin Orthop Relat Res. 2009;467:660-665.

40. Ranawat A, Schulz B, Baumbach S, Meftah M, Ganz R, Leunig M. Radiographic predictors of hip pain in femoroacetabular impingement. HSS J. 2011;7:115-119.

41. Reynolds D, Lucas J, Klaue K. Retroversion of the acetabulum. A cause of hip pain. J Bone Joint Surg Br. 1999;81:281-288.

42. Shrout PE, Fleiss JL. Intraclass correlations: uses in assessing rater reliability. Psychol Bull. 1979;86:420-428.

43. Sutter R, Dietrich TJ, Zingg PO, Pfirmann CWA. How useful is the alpha angle for discriminating between symptomatic patients with cam-type femoroacetabular impingement and asymptomatic volunteers? Radiology. 2012;264:514-521.

44. Tabachnick BG, Fidell LS. Using Multivariate Statistics. 5th ed. Boston, MA, USA: Pearson Education, Inc; 2007.

45. Tannast M, Siebenrock KA, Anderson SE. Femoroacetabular impingement: radiographic diagnosis-what the radiologist should know. AJR Am J Roentgenol. 2007;188:1540-1552.

46. Tibor LM, Leunig M. The pathoanatomy and arthroscopic management of femoroacetabular impingement. Bone Joint Res. $2012 ; 1: 245-257$ 